\title{
HOUSEHOLD ENVIRONMENTAL TOBACCO SMOKE AND RESPIRATORY DISEASES AMONG CHILDREN IN NIŠ (SERBIA)
}

\author{
Ljiljana Stošić1, Suzana Milutinović1, Konstansa Lazarević1, Ljiljana Blagojević ${ }^{2}$ Ljiljana Tadić \\ ${ }^{1}$ Public Health Institute, Niš, Serbia \\ ${ }^{2}$ Faculty of Occupational Safety Niš, Serbia \\ ${ }^{3}$ Internal Department of Military Hospital Niš, Serbia
}

\begin{abstract}
SUMMARY
The authors investigated the relationship between household environmental tobacco smoke (ETS) exposure and prevalence of respiratory symptoms and diseases as well as absenteeism related to respiratory illness in schoolchildren. The study sample consisted of 1,074 children aged 7-11 years from three primary schools in Niš (Serbia). ETS exposure was associated with wheezing (OR-1.48; 1.09-2.01), bronchitis (OR-1.66; 1.23-2.23), headache (OR-1.45; 1.08-1.95), and fatigue (OR-1.38; 1.02-1.85) in exposed children. The other risk factors with possible influences weren't assessed. There was no statistically significant difference in the number of physicians' visits as well as in absenteeism from school due to illness in children exposed to ETS in comparison to non exposed children. The tobacco smoke effect on children is an essential and urgent problem with life lasting negative health effects which are preventable.
\end{abstract}

Key words: environmental tobacco smoke, respiratory diseases

Address for correspondence: L. Stošić, Public Health Institute Niš, Dr Zorana Đinđica 50, Niš, Serbia. E-mail: ljstosic@live.com

\section{INTRODUCTION}

Household environmental tobacco smoke (ETS) is a major source of indoor air contaminants and it presents an important public health problem (1). Environmental tobacco smoke is a dynamic, complex mixture of more than 4,000 chemicals found in both vapour and particle phases. Many of these chemicals are known toxic or carcinogenic agents.

Many previous studies have shown that a large number of children are exposed to environmental tobacco smoke in their homes (2-4). The World Health Organization estimated that approximately half of the children in the world are exposed to ETS, mostly in their homes (5). In the United States, approximately $60 \%$ of children aged 3 to 11 years are exposed to secondhand smoke (6) and $25 \%$ live with one or more smokers in their home (7).

Children are particularly vulnerable to the harmful effects of environmental tobacco smoke because of their relatively underdeveloped immune and pulmonary systems, their small body size, and their higher rates of ventilation $(8,9)$.

Exposures to ETS have been associated with a variety of adverse health effects in children. Several recent studies link ETS with increased incidence and prevalence of asthma and increased severity of asthmatic symptoms in children of mothers who smoke heavily (10). These respiratory illnesses in childhood may very well contribute to the significant lung function reductions associated with exposure to ETS in adults. There is also strong evidence of increased middle ear effusion (11), reduced lung function, and reduced lung growth (12). Some U.S. studies have also shown a relationship between environmental tobacco smoke and cognitive abilities among children and adolescents (13).

The aim of this study was to estimate the effects of environmental tobacco smoke on prevalence of respiratory symptoms and diseases as well as absenteeism related to respiratory illness in schoolchildren.

\section{MATERIALS AND METHODS}

Three primary schools in Niš (Serbia) with a total of 1,309 children aged 7 to 11 years were chosen randomly. Assessment of exposure to ETS was done by using the original questionnaire. Trained physicians filled in questionnaires during interviews with children's parents. The study sample consisted of 1,074 children and the response rate was $82 \%$.

Exposure of children to ETS was examined on the basic responses to following questions: "Does anyone smoke in the house?", and "How many smokers live at home?".

The second part of the questionnaire was about prevalence of respiratory symptoms (nasal congestion, nasal secretion, dyspnea, wheezing, cough), respiratory diseases (sinusitis, bronchitis, asthma, pneumonia), nonspecific symptoms (watery eyes, dry throat, headache, fatigue) and absenteeism related to respiratory illness in children in the past 12 months. Respiratory diseases were considered if an affirmative answer was given to the following questions: "Has any doctor diagnosed your child with asthma 
(sinusitis, bronchitis, pneumonia)?" The other risk factors of the given symptoms and diseases were not followed.

Investigated children were divided into two groups: exposed and non exposed to ETS. In both groups, prevalence of symptoms and disease was scrutinized. Interview data were analysed using programmes Epi Info 6 and Microsoft Excel. Statistical significance of difference is established by Pearson's chi-squared test. The odds ratio and $95 \%$ confidence interval were calculated to evaluate the presence of associations between all symptoms and diseases in the children and ETS.

\section{RESULTS}

Studied sample included 554 (51.60\%) boys and 520 (48.40\%) girls. The average (mean) age was 9.067 (SD-1.297) for boys and 9.096 (SD-1.233) for girls (Table 1).

It was found out that $69.65 \%$ of examinees were exposed to ETS. Most exposed children live in households with one smoker, a smaller number of children live with two smokers (Table 2).

It is reported in this investigation that parental smoking was significantly associated with wheezing $(\mathrm{OR}=1.48 ; 1.09-2.01)$, bronchitis $(\mathrm{OR}=1.66 ; 1.23-2.23)$, headache $(\mathrm{OR}=1.45 ; 1.08-$ $1.95)$, and fatigue $(\mathrm{OR}=1.38 ; 1.02-1.85)$ in exposed children. Data are presented in Table 3.

There was no statistically significant difference in the number of physicians' visits, as well as in absenteeism from school due to illness in children exposed to passive smoking compared to non exposed children (Table 4, 5).

\section{DISCUSSION}

This research has established a high level of indoor exposure to ETS in children in their families. Of the total number of respondents nearly $70 \%$ of children were exposed to this source of air pollution. We also found association between ETS and respiratory diseases. It has been determined that incidence of bronchitis in children exposed to ETS was higher. Consequently, wheezing, headache, and fatigue were more frequent in the exposed children.

Other investigations, but not all, give similar results. Strachan and Carey at Sheffield found on a sample of children aged 11

Table 1. Characteristics of the population study

\begin{tabular}{|l|c|c|}
\hline Sex & Number (\%) & Mean age \\
\hline Male & $554(51.60)$ & $9.067 \pm 1.297$ \\
\hline Female & $520(48.40)$ & $9.096 \pm 1.233$ \\
\hline
\end{tabular}

Table 2. Number of smokers in household

\begin{tabular}{|c|c|c|c|c|c|}
\hline \multicolumn{5}{|c|}{ Number of smokers in household } & \multirow{2}{*}{ Total } \\
\hline 1 & 2 & 3 & 4 & $\begin{array}{c}\text { without } \\
\text { smokers }\end{array}$ & \\
\hline 388 & 326 & 28 & 7 & 325 & 1074 \\
$(36.13 \%)$ & $(30.35 \%)$ & $(2.61 \%)$ & $(0.65 \%)$ & $(30.26 \%)$ & 1074 \\
\hline
\end{tabular}

to 16 years, that wheezing had been more frequent in children whose mothers smoked more than ten cigarettes a day and that the relative risk is 2.28 (14). The consequences of exposure to ETS were also studied in Boston on a sample of children aged 7 to 12 years (15). It was found that in exposed children relative risk of cough is higher $(\mathrm{RR}=12.4, \mathrm{CI}=2.4-63.3)$ and they have used bronchodilators more frequently $(\mathrm{RR}=10.3, \mathrm{CI}=1.3-83.7)$. A group of scientists in Portugal have shown a positive relationship of ETS exposure with the occurrence of respiratory symptoms (cough and wheeze) but not with asthma (16).

Prevalence studies in school age children suggest respiratory infections, wheezing, and asthma are more frequent in children whose parents smoke $(17,18)$.

For example, Mc Kenzi and Bush have concluded that exposure to ETS can worsen symptoms in children with asthma (3).

A group of scientists in Brazil (2) examined the impact of exposure to tobacco smoke in preschool children. More than half of surveyed children were exposed to ETS, and $82 \%$ of children exposed to this risk factor had respiratory problems: cough $(\mathrm{OR}=1.58 ; \mathrm{CI}=1.09-2.28)$, wheezing in the chest $(\mathrm{OR}=1.91$; $\mathrm{CI}=1.36-2.67)$ and respiratory diseases (asthma, bronchitis and pneumonia) $(\mathrm{OR}=1.11 ; \mathrm{CI}=1.11-2.31)$. Increased incidence of lower respiratory tract infections and asthma in children aged 4 to 9 years were found in another research in Brazil (19).

There is a limited evidence of ETS exposure and nonspecific symptoms among exposed schoolchildren.

This study found no statistically significant difference in the number of physicians' visits as well as in absenteeism from school due to illness in children exposed to ETS in comparison to not exposed children.

However, the results of other studies show that exposure to ETS is connected with high absenteeism from school due to problems with the respiratory system. A group of scientists in 12 cities in Southern California (20) examined the impact of ETS on asthma status of children and their absenteeism from the school due to respiratory disease. The investigation encompassed nearly 2,000 children. It has shown a significant effect of ETS exposure on absenteeism from the school due to respiratory disease $(R R=1.27$; $\mathrm{CI}=1.04-1.56)$. Compared with children who do not suffer from asthma and who are not exposed to ETS, children with asthma who live even with only one smoker are more likely to miss school $(\mathrm{RR}=2.35)$, and children living with two smokers miss school even more $(\mathrm{RR}=4.45)$.

School absenteeism due to respiratory diseases in children exposed to ETS was confirmed by other authors as well $(21,22)$.

Our study has some limitations. A retrospective questioning of children's parents about children morbidity in the past 12 month might have confounding effect despite being done by medical staff. Also, the sum of physician visits without distinguishing among reasons (diagnoses) and dates (seasons) is certainly not a sensitive way how to compare the health of exposed and nonexposed children. Chronic illnesses (e.g., allergies) were not taken into consideration as well as household conditions, socioeconomic status of families, education of parents, gender of children, exposure to airpollution etc. We were unable to investigate any dose-response relatioships because we lacked infomation on the intensity or duration of exposure. Moreover, it is possible that at this age some children from nonsmoking families were exposed to ETS outside their homes. 
Table 3. ETS exposure and observed symptoms

\begin{tabular}{|c|c|c|c|c|c|c|c|}
\hline \multirow{3}{*}{$\begin{array}{l}\text { Symptoms and } \\
\text { diseases** }\end{array}$} & \multicolumn{4}{|c|}{ Number (\%) } & \multirow{3}{*}{$x^{2}$} & \multirow{3}{*}{$\mathrm{OR}$} & \multirow{3}{*}{$\mathrm{Cl}$} \\
\hline & \multicolumn{2}{|c|}{ Exposed } & \multicolumn{2}{|c|}{ Non exposed } & & & \\
\hline & Yes & No & Yes & No & & & \\
\hline Nasal congestion & $589(78.6)$ & $160(21.4)$ & $238(73.2)$ & $87(26.7)$ & 3.74 & 1.35 & $0.98-1.84$ \\
\hline Nasal secretion & $390(52.1)$ & $359(47.9)$ & $168(51.7)$ & $157(48.3)$ & 0.01 & 1.02 & $0.78-1.33$ \\
\hline Difficulty breathing & $101(13.5)$ & $648(86.5)$ & $43(13.2)$ & $282(86.8)$ & 0.01 & 1.02 & $0.69-1.53$ \\
\hline Wheezing & $241(32.2)$ & $508(67.8)$ & $79(24.3)$ & $246(75.7)$ & $6.71^{*}$ & 1.48 & $1.09-2.01$ \\
\hline Cough & $147(19.6)$ & $602(80.4)$ & $59(18.2)$ & $266(81.8)$ & 0.32 & 1.1 & $0.78-1.56$ \\
\hline Sinusitis & $19(2.5)$ & $730(97.5)$ & $9(2.8)$ & $316(97.2)$ & 0.05 & 0.91 & $0.39-2.21$ \\
\hline Bronchitis & $277(37.0)$ & $472(63.0)$ & $85(26.2)$ & $240(73.8)$ & $11.89^{*}$ & 1.66 & $1.23-2.23$ \\
\hline Asthma & $23(3.1)$ & $726(96.9)$ & $8(2.5)$ & $317(97.5)$ & 0.3 & 1.26 & $0.53-3.08$ \\
\hline Pneumonia & $100(13.4)$ & $649(86.6)$ & 37 (11.4) & $288(88.6)$ & 0.79 & 1.2 & $0.79-1.83$ \\
\hline Watery eyes & $119(15.9)$ & $630(84.1)$ & 38 (11.7) & $287(88.3)$ & 3.2 & 1.43 & $0.95-2.15$ \\
\hline Dry throat & $150(20.0)$ & $599(80.0)$ & $57(17.5)$ & $268(82.5)$ & 0.9 & 1.18 & $0.83-1.67$ \\
\hline Headache & $262(35.0)$ & $487(65.0)$ & $88(27.1)$ & $237(72.9)$ & $6.44^{*}$ & 1.45 & $1.08-1.95$ \\
\hline Fatigue & $261(34.8)$ & $488(65.2)$ & $91(28.0)$ & $234(72.0)$ & $4.82^{*}$ & 1.38 & $1.02-1.85$ \\
\hline
\end{tabular}

${ }^{*} p<0.05$

** only once

Table 4. Exposure to passive smoking and the number of physicians' visits due to problems with respiratory system for the past year

\begin{tabular}{|c|c|c|c|c|c|c|}
\hline \multirow{2}{*}{ Passive smoking } & \multicolumn{4}{|c|}{ Number of physicians' visits } & \multirow{2}{*}{ Total } & \multirow{2}{*}{$x^{2}$} \\
\hline & Not one & $1-3$ & $4-6$ & $>6$ & & \\
\hline Yes & $\begin{array}{c}238 \\
(22.16 \%)\end{array}$ & $\begin{array}{c}416 \\
(38.73 \%)\end{array}$ & $\begin{array}{c}75 \\
(6.98 \%)\end{array}$ & $\begin{array}{c}20 \\
(1.86 \%)\end{array}$ & $\begin{array}{c}749 \\
(69.74 \%)\end{array}$ & \multirow{3}{*}{$\begin{array}{l}x^{2}=2.85 \\
p>0.05\end{array}$} \\
\hline No & $\begin{array}{c}117 \\
(10.89 \%)\end{array}$ & $\begin{array}{c}176 \\
(16.39 \%)\end{array}$ & $\begin{array}{c}25 \\
(2.33 \%)\end{array}$ & $\begin{array}{c}7 \\
(0.65 \%)\end{array}$ & $\begin{array}{c}325 \\
(30.26 \%)\end{array}$ & \\
\hline Total & $\begin{array}{c}355 \\
(33.05 \%)\end{array}$ & $\begin{array}{c}592 \\
(55.12 \%)\end{array}$ & $\begin{array}{c}100 \\
(9.31 \%)\end{array}$ & $\begin{array}{c}27 \\
(2.51 \%)\end{array}$ & $\begin{array}{c}1074 \\
(100 \%)\end{array}$ & \\
\hline
\end{tabular}

Table 5. Exposure to tobacco smoke and absenteeism from school due to illness for the past year

\begin{tabular}{|c|c|c|c|c|c|c|}
\hline \multirow{2}{*}{ Passive smoking } & \multicolumn{4}{|c|}{ Absenteeism from school } & \multirow{2}{*}{ Total } & \multirow{2}{*}{$x^{2}$} \\
\hline & Not one & $1-3$ & $4-6$ & $>6$ & & \\
\hline Yes & $\begin{array}{c}240 \\
(22.35 \%)\end{array}$ & $\begin{array}{c}423 \\
(39.39 \%)\end{array}$ & $\begin{array}{c}66 \\
(6.15 \%)\end{array}$ & $\begin{array}{c}20 \\
(1.86 \%)\end{array}$ & $\begin{array}{c}749 \\
(69.74 \%)\end{array}$ & \multirow{3}{*}{$\begin{array}{l}x^{2}=7.18 \\
p>0.05\end{array}$} \\
\hline No & $\begin{array}{c}122 \\
(11.36 \%)\end{array}$ & $\begin{array}{c}181 \\
(16.85 \%)\end{array}$ & $\begin{array}{c}16 \\
(1.49 \%)\end{array}$ & $\begin{array}{c}6 \\
(0.56 \%)\end{array}$ & $\begin{array}{c}325 \\
(30.26 \%)\end{array}$ & \\
\hline Total & $\begin{array}{c}362 \\
(33.71 \%)\end{array}$ & $\begin{array}{c}604 \\
(56.24 \%)\end{array}$ & $\begin{array}{c}82 \\
(7.64 \%)\end{array}$ & $\begin{array}{c}26 \\
(2.42 \%)\end{array}$ & $\begin{array}{c}1074 \\
(100 \%)\end{array}$ & \\
\hline
\end{tabular}

\section{CONCLUSIONS}

However, our findings have practical and public health significance. This study confirmed that environmental tobacco smoke endangers children's health. The only way to fully protect children from tobacco smoke is to completely stop the habit of cigarette smoking in households and increase parents' knowledge about smoking health hazards. Even though there are laws in Serbia (23) that protect non-smokers from ETS exposure in public and work places there are no measures in force to protect children in their home indicating that involuntary secondhand smoke exposure and significant morbidity will persist. Because of that Public Health authorities should develop strategies to reduce tobacco smoke in the home environment. ETS awareness and control strategies for 
households should also be incorporated into mandatory tobacco education programmes in schools.

\section{REFERENCES}

1. Keskinoglu P, Cimrin D, Aksakoglu G. The impact of passive smoking on the development of lower respiratory tract infections in children. J Trop Pediatr. 2007 Oct;53(5):319-24.

2. Pereira ED, Torres L, Macêdo J, Medeiros MM. Effects of environmental tobacco smoke on lower respiratory system of children under 5 years of age. Rev Saude Publica. 2000 Feb;34(1):39-43. (In Portuguese.)

3. McKenzie SA, Bush A. Difficult asthma in children. Arch Dis Child. $2003 \mathrm{Feb} ; 88(2): 168-9$.

4. Boyaci H, Duman C, Başyiğit I, Ilgazli A, Yildiz F. Determination of environmental tobacco smoke in primary school children with urine cotinine measurements. Tuberk Toraks. 2004;52(3):231-6. (In Turkish.)

5. World Health Organization. Media centre. Tobacco: fact sheet no. 339 [Internet]. Geneva: WHO; 2011 [cited 2011 Jul 10]. Available from: http:// www.who.int/mediacentre/factsheets/fs339/en/.

6. U. S. Department of Health and Human Services. The health consequences of involuntary exposure to tobacco smoke: a report of the Surgeon General, U. S. Department of Health and Human Services. Secondhand smoke exposure in the home [Internet]. Washington: U. S. Department of Health and Human Services; 2007 [updated 2007 Jan 4; cited 2008 Apr 16]. Available from: http://www.surgeongeneral.gov/library/secondhandsmoke/factsheets/factsheet4.html.

7. Pirkle JL, Bernert JT, Caudill SP, Sosnoff CS, Pechacek TF. Trends in the exposure of nonsmokers in the U.S. population to secondhand smoke: 1988-2002. Environ Health Perspect. 2006 Jun;114(6):853-8.

8. U.S. Department of Health and Human Services. Children and secondhand smoke exposure. Excerpts from the health consequences of involuntary exposure to tobacco smoke: a report of the surgeon general. Rockville, MD: U.S. Department of Health and Human Services, Public Health Service, Office of the Surgeon General; 2007.

9. Randall S. Children and secondhand smoke: not just a community issue. Paediatr Nurs. 2006 Mar;18(2):29-31.

10. Mannino DM, Homa DM, Akinbami LJ, Moorman JE, Gwynn C, Redd SC. Surveillance for asthma - United States, 1980-1999. MMWR Surveill Summ. 2002 Mar 29;51(1):1-13.
11. Ey JL, Holberg CJ, Aldous MB, Wright AL, Martinez FD, Taussig LM; Group Health Medical Associates. Passive smoke exposure and otitis media in the first year of life. Pediatrics. 1995 May;95(5):670-7.

12. Tutka P, Wielosz M, Zatoński W. Exposure to environmental tobacco smoke and children health. Int J Occup Med Environ Health. 2002; 15(4):325-35.

13. Yolton K, Dietrich K, Auinger P, Lanphear BP, Hornung R. Exposure to environmental tobacco smoke and cognitive abilities among U.S. children and adolescents. Environ Health Perspect. 2005 Jan;113(1):98-103.

14. Strachan DP, Carey IM. Home environment and severe asthma in adolescence: a population based case-control study. BMJ. 1995 Oct 21;311(7012):1053-6

15. Schwartz J, Timonen KL, Pekkanen J. Respiratory effects of environmental tobacco smoke in a panel study of asthmatic and symptomatic children. Am J Respir Crit Care Med. 2000 Mar;161(3 Pt 1):802-6.

16. Constant C, Sampaio I, Negreiro F, Aguiar P, Silva A, Salgueiro M, et al. Environmental tobacco smoke (ETS) exposure and respiratory morbidity in school age children. Rev Port Pneumol. 2011 Jan-Feb;17(1):20-6.

17. Gilliland FD, Li YF, Peters JM. Effects of maternal smoking during pregnancy and environmental tobacco smoke on asthma and wheezing in children. Am J Respir Crit Care Med. 2001 Feb;163(2):429-36.

18. Jaakkola JJ, Jaakkola MS. Effects of environmental tobacco smoke on the respiratory health of children. Scand J Work Environ Health. 2002;28 Suppl 2:71-83.

19. Ribeiro SA, Furuyama T, Schenkman S, Jardim JR. Atopy, passive smoking, respiratory infections and asthma among children from kindergarten and elementary school. Sao Paulo Med J. 2002 Jul 4;120(4):109-12.

20. Gilliland FD, Berhane K, Islam T, Wenten M, Rappaport E, Avol E, et al. Environmental tobacco smoke and absenteeism related to respiratory illness in schoolchildren. Am J Epidemiol. 2003 May 15;157(10):861-9.

21. Strachan DP, Cook DG. Health effects of passive smoking. 1. Parental smoking and lower respiratory illness in infancy and early childhood. Thorax. 1997 Oct;52(10):905-14.

22. Freeman NC, Schneider D, McGarvey P. Household exposure factors, asthma, and school absenteeism in a predominantly Hispanic community. J Expo Anal Environ Epidemiol. 2003 May;13(3):169-76.

23. Law on preventing population from exposure to tobacco smoke. Official Gazette RS. 2010:30. 